\title{
O "Programa Alfabetização Solidária": terceirização no contexto da Reforma do Estado 1
}

\section{"Programa Alfabetização Solidária" Literacy Program and State Reform in Brazil}

\author{
Gladys Beatriz Barreyro²
}

\begin{abstract}
RESUMO
O presente trabalho busca analisar o Programa Alfabetização Solidária a partir de um modelo de Estado proposto pelo governo do presidente Fernando Henrique Cardoso (1997-2002). Considera-se que a proposta de Reforma do Estado ali desenvolvida, a partir do conceito de publicização, teve sua derivação na área social-assistencial do governo na Comunidade Solidária, um ensaio de terceirização na área das políticas sociais. O Alfabetização Solidária, subprograma deste, foi a versão para a área de educação. De modo que algumas características desse Programa específico devem ser discutidas e contextualizadas à luz de um marco mais amplo, analisando conceitos como terceirização, filantropia, empregabilidade temporária, participação social e direito à educação.

Palavras-chave: educação de jovens e adultos; Programa Alfabetização Solidária; políticas de alfabetização de adultos.
\end{abstract}

\begin{abstract}
This article analyses the "Programa de Afabetização Solidária" Literacy Program as a product of the model of State proposed during the two presidential terms of Fernando Henrique Cardoso (1997-2002), in Brazil. I analysed the proposal of State Reform based on publicization and its counterpart in the social-assistance area of the government: the creation of the Solidarity
\end{abstract}

1 O texto é uma síntese e re-elaboração de aspectos da tese de doutoramento em educação da autora (BARREYRO, 2005), que contou com financiamento do Conselho Nacional de Desenvolvimento Científico e Tecnológico (CNPQ) (PEC/PG) e da Coordenação de Aperfeiçoamento de Pessoal de Nível Superior (CAPES). Uma versão do texto foi apresentada na $29^{\text {a }}$ Reunião Anual da Associação Nacional de Pós-graduação em Educação (ANPED) Educação, cultura e conhecimento na contemporaneidade. Desafios e compromissos, Caxambu, 13 de outubro de 2006 e publicada nos Anais do Evento, em CDRom.

2 Doutora em Educação. Professora na Universidade de São Paulo - Brasil, Programa de PósGraduação em Educação e Escola de Artes, Ciências e Humanidades (EACH). 
Community ("Comunidade Solidária"). This was a test of outsourcing in the social policy area and the "Programa de Afabetização Solidária"Solidarity in Literacy Program, which arose as a subproject of that one, was a laboratory that developed that State model in the educational area. For this reason, some characteristics of this Program are discussed within that frame and concepts like outsourcing, philanthropy, use of cheap and temporary labor force, participation and right to education are analyzed.

Keywords: youth and adult education;"Programa Alfabetização Solidária"; adult literacy policies in Brazil.

\section{Introdução}

Em setembro de 1996 foi realizado em Natal, RN, o Seminário Nacional de Educação de Jovens e Adultos. Foi a culminação de diversos encontros estaduais e regionais, com a participação de universidades, organizações não governamentais, setor público, sistema "S", etc., que haviam sido promovidos pelo Ministério da Educação (MEC), por recomendação da Comissão Nacional de Educação de Jovens e Adultos (CNEJA). Com o intuito de participar, no ano seguinte, da V Conferência Internacional sobre Educação de Jovens e Adultos (CONFINTEA), em Hamburgo, na Alemanha, nesse Seminário foram articuladas as propostas dos encontros anteriores e redigido um Documento Final, aprovado na sessão plenária (UNESCO/MEC, 2004).

Nesse mesmo seminário, que consolidava as propostas dos distintos setores atuantes na educação de jovens e adultos (EJA), foi apresentado o Programa Alfabetização Solidária. Uma proposta já elaborada que contrastava com o conteúdo do Documento e com a prática de construção social da EJA.

O Documento Final do Seminário não foi oficializado pelo governo brasileiro, que o desconsiderou e, aliás, exonerou à Coordenadora de Educação de Jovens e Adultos da Secretaria do Ensino Fundamental do MEC (SOARES, 2002), evidenciando discordâncias entre o governo e a sociedade civil, a respeito das políticas de educação de jovens e adultos.

O Programa Alfabetização Solidária manifestava como objetivo reduzir os índices de analfabetismo do país, focalizando nos jovens de 12 a 18 anos. Em 1997, priorizava os municípios com taxas de analfabetismo superiores a 55\%: os localizados nas regiões norte e nordeste. Em 1999, atingiu os Grandes Centros Urbanos e, em 2002, as regiões Centro-Oeste e Sudeste.

Atuava mediante as chamadas "parcerias": com empresas que custeavam metade dos gastos por aluno (a outra metade era coberta com fundos públicos, 
advindos do MEC); com universidades, que executavam as ações de alfabetização por meio de coordenadores e alfabetizadores que elas selecionavam e capacitavam; com os municípios, que eram responsáveis por questões operacionais (salas de aula, merenda, convocatórias). Os alfabetizadores eram pessoas do próprio município ou estudantes das universidades que recebiam um curso de capacitação. As aulas estavam organizadas em módulos de seis meses de duração cada um, e os alunos e alfabetizadores apenas podiam participar de um módulo.

O Programa Alfabetização Solidária era um subprograma da Comunidade Solidária, estratégia do governo para a gestão das políticas públicas, que desenvolvia programas inovadores. No entanto, algumas das suas características inovadoras, tais como parcerias com empresas, duração dos módulos, mudança de alfabetizador após seis meses de desempenho, utilização de alfabetizadores leigos, entre outras, só podem ser entendidas se o Programa for considerado a partir do seu contexto histórico. Portanto, este trabalho analisa e discute o Programa Alfabetização Solidária, considerando a Reforma do Estado em curso nessa época, as novas características das políticas sociais e, ainda, sua vinculação com a Comunidade Solidária, da qual surgiu.

\section{A Reforma do Estado, a publicização e o terceiro setor}

Quando o Programa Alfabetização Solidária foi criado, a América Latina estava implementando políticas sociais acordes com o modelo de Estado que, na década de 1990, havia se consolidado na região. Os estados latino-americanos pós-reformas adotavam políticas sociais compensatórias, cujas principais marcas eram a focalização, a descentralização e a privatização, adaptadas às características de cada país (DI PIERRO, 2001).

No Brasil, o governo implementou sua própria Reforma do Estado que, além das numerosas privatizações (como era comum na época em toda a América Latina), continha elementos originais. O ministro Bresser Pereira, no Ministério da Administração Federal e Reforma do Estado - MARE (grifo meu) propunha a instalação de uma administração gerencial que superasse as limitações da administração pública burocrática. Para tanto, o Plano Diretor da Reforma do Aparelho do Estado (BRASIL, 1995) distinguia setores estratégicos de atividades exclusivas do Estado, que deveriam ser mantidas: o núcleo estratégico (Presidência, Ministérios de Estado e Tribunais Federais) e as atividades exclusivas do Estado (poder de legislar e tributar, de polícia, forças armadas, órgãos de fiscalização 
e de regulamentação). Outros setores como os de produção de bens e serviços para o mercado (empresas de economia mista em setores estratégicos ou de serviços públicos) deveriam ser repassados para a iniciativa privada.

A novidade estava nos setores definidos como serviços não exclusivos ou competitivos do Estado, aqueles que não envolvem seu poder - segundo a argumentação no Plano - mas são realizados ou subsidiados por ele, pois são considerados de importância para os direitos. No caso, a proposta considera que esses serviços passem a ser de propriedade pública não-estatal, distinguindo um terceiro tipo, além da privada e da pública estatal. Essa terceira forma de propriedade inclui " [...] as instituições de direito privado voltadas para o interesse público e não para o consumo privado, [porque] não são privadas, e sim públicas não estatais" (PEREIRA, 1998, p. 262). Essa propriedade “... deve ser pública para justificar os subsídios recebidos do Estado" (PEREIRA, 1998, p. 263). Segundo a proposta, o controle do Estado deve ser complementado pelo controle social direto, mediante os conselhos de administração da sociedade. Desta forma, estabelece-se "[...] um sistema de parceria ou de co-gestão entre o Estado e a sociedade civil" (PEREIRA, 1998, p. 263).

Como se percebe, a reforma administrativa do Estado apóia-se na publicização das atividades que, nessa concepção, não são exclusivas a ele: serviços sociais, culturais, de proteção ambiental, de pesquisa científica e tecnológica, as quais, segundo a proposta, seriam atividades públicas não-estatais, e ganhariam em qualidade e eficiência se fossem publicizadas. As subvenções sociais e as dotações orçamentárias seriam transferidas do poder público, porque as organizações sociais seriam reconhecidas como de interesse e utilidade pública e, por isso, habilitadas a receber recursos financeiros e a gerenciar recursos materiais e humanos cedidos pelo Estado. Para viabilizar a proposta, foi criado o Programa Nacional de Publicização e as organizações sociais, consideradas pessoas jurídicas de direito privado, que funcionariam como associações civis sem fins lucrativos.

Assim, entidades que prestam serviços não exclusivos do Estado, como escolas técnicas, centros de pesquisa, hospitais e museus, seriam transformadas em organizações sociais. Depois, essas instituições sairiam do âmbito estatal e passariam a ser regidas pelo direito privado, dispondo de autonomia financeira e administrativa (BARRETO, 1998). Receberiam, ainda, o patrimônio e o pessoal da entidade e os recursos cedidos pelo governo ${ }^{3}$.

Em síntese, a proposta brasileira de Reforma do Estado propôs tanto a superação da administração pública burocrática quanto a sua substituição pela

3 Para uma descrição detalhada da conversão das instituições em organizações da sociedade civil, requisitos e normas, ver Barreto (1998). 
administração gerencial, construindo, a partir do conceito de público não-estatal e de publicização, uma privatização à brasileira.

É importante relembrar esse contexto, pois a implantação desse modelo de publicização foi concomitante ao desenvolvimento de outras estratégias políticas com a mesma lógica. No âmbito das políticas sociais, a Comunidade Solidária iniciava um movimento de mudança, pelo Estado, na provisão de certos serviços e direitos, promovendo um modelo de terceirização de políticas sociais, ainda vigente.

A Comunidade Solidária, nos seus primórdios, ligava-se à distribuição de cestas básicas, mas foi muito criticada, o que o levou a mudar de foco, escolhendo alguns eixos de trabalho tais como: fortalecimento da sociedade civil (que se concentrou na promoção do voluntariado e do "terceiro setor") e o desenvolvimento de programas inovadores: (FRANCO, 2000).

A área da Comunidade Solidária relacionada ao fortalecimento da sociedade civil promoveu o voluntariado e o terceiro setor. Documentos oficiais assinalam que estimular o crescimento do terceiro setor implicava o fortalecimento da Sociedade Civil (FERRAREZI, 2000) e a ação mais destacada foi a criação do Marco Legal do Terceiro Setor. Para isso, contou-se com o financiamento do Banco Interamericano de Desenvolvimento (BID), entidade que promovia, em seus documentos gerais para toda a América Latina:

[...] el fortalecimento de las organizaciones de la sociedad civil (OSC): la promoción de un marco jurídico que propicie la asociación y participación de los ciudadanos, la identificación de nuevas formas de prestación de los servicios sociales a través de los gobiernos locales y las organizaciones intermedias y de base; la promoción de la filantropia y el voluntariado (BID, ,[19-?], p. 20).

Assim, havia coerência entre a Reforma Administrativa do Estado Brasileiro e a terceirização realizada na área das políticas sociais. A legislação, vigente até hoje, pôde outorgar às Instituições o Certificado de Fins Filantrópicos e o Certificado de Utilidade Pública Federal, isentando-as de impostos. Mas, para poder terceirizar a execução das políticas, seria preciso mudar a legislação. Por isso, a Comunidade Solidária concentrou as atividades que culminaram na sanção da Lei 9790/994,

4 Para um aprofundamento sobre o processo de criação da lei, ver as publicações do Conselho da Comunidade Solidária financiadas pelo BID: Falcão e Cuenca (1999) e de Ferrarezi (2000), assessora do Conselho. 
que criou as Organizações da Sociedade Civil de Interesse Público (OSCIPs), visando incluir, dentro do público, as organizações que se dedicam ao desenvolvimento humano e social sustentável, à promoção da assistência social, à cultura, à educação gratuita, à conservação do patrimônio, à saúde gratuita, à segurança alimentar e nutricional, à defesa do meio ambiente, à promoção do voluntariado, ao combate à pobreza, à promoção de direitos, aos estudos e pesquisas (art. $3^{\circ}$ ), ou seja, as Organizações não Governamentais (ONGs).

A nova lei estabelecia, também, o Termo de Parceria, instrumento mediante o qual o Poder Público é facultado a repassar recursos para a implementação das políticas públicas. Destaca-se, no artigo $2^{\circ}$ da Lei, a exclusão de entidades como movimentos sociais e cooperativas, da qualificação de Organizações da Sociedade Civil e, portanto, da execução de tarefas de serviço público, evidenciando a concepção de sociedade civil que, para a Comunidade Solidária, parece se limitar às $\mathrm{ONGs}^{5}$.

Enfim, a elaboração de uma legislação para regulamentar esse setor foi uma das prioridades da Comunidade Solidária, sendo que, por essa via, o Estado brasileiro criou, também, condições necessárias para viabilizar o processo de terceirização de políticas sociais, contando com financiamento do BID para essas ações.

O Programa Alfabetização Solidária, como já foi assinalado, fez parte da segunda linha de ação da Comunidade Solidária, dos chamados programas inovadores, e sempre teve relação com aquela, até depois de passar a ser gestionada por uma “ONG”, a rigor uma Associação de Apoio 6 . Por exemplo, a Dra. Ruth Cardoso, presidente da Comunidade Solidária e, depois da mudança de governo, em 2003, do Comunitas ${ }^{7}$, sempre compareceu aos eventos anuais do Programa, Semanas da Alfabetização, o que confirma a relação.

\section{Terceirização de políticas educacionais?}

5 A perspectiva aqui adotada tenta mostrar essa lei como um elemento que facilita a terceirização de políticas públicas do Estado. Não implica numa desqualificação das ONGs, mas analisa suas consequências no objeto de estudo.

6 Não existe a figura jurídica de Organização não governamental (ONG) no Brasil. AAssociação é "uma organização sem fins lucrativos e de utilidade pública" (<www.alfabetizaçãosolidária.org.>, acesso em: 3/12/2001).

7 A organização civil sem fins lucrativos Comunitas foi criada para "dar continuidade e fortalecer o trabalho iniciado pela Comunidade Solidária" ( $<$ www.comunitas.org.br $>$, acesso em: $18 / 05 / 2004)$. 
O primeiro aspecto a ser aqui analisado é a reiteração da independência do Estado e do governo que tanto a Comunidade Solidária quanto o Programa Alfabetização Solidária postulavam.

Concordando com as estratégias de publicização desenvolvidas pelo MARE, a Comunidade Solidária afirmava: "[...] não se trata mais de um sinônimo de política governamental. Política pública é aquela que se realiza em espaço público, com o concurso de atores governamentais e não governamentais, estatais e não estatais" (FRANCO, 2000, p. 81).

Aliás, a própria Ruth Cardoso, mesmo em seu posto de Primeira Dama, dizia à época, na $2^{\text {a }}$ semana da Alfabetização: "Não somos Governo" (CARDOSO, 2001). Essa questão levou o então ministro da Educação, Paulo Renato Souza, a se manifestar: "Isso é um absurdo! Se não fosse o Governo, o Programa não teria existido. Criamos o Alfabetização Solidária, e o governo paga $50 \%$ dos gastos dele..." (REPÚBLICA, 2001, p. 41).

A rigor, os recursos recebidos do Governo Federal foram importantes, como mostra a tabela a seguir, tendo aumentado muito nos últimos dois anos do governo Fernando Henrique Cardoso.

TABELA 1 - RECURSOS DO GOVERNO FEDERAL PARA O PROGRAMAALFABETIZAÇÃO SOLIDÁRIA 2000-2004

\begin{tabular}{c|c}
\hline Ano & Recursos Recebidos do Governo Federal (em reais) \\
\hline 2000 & $24.302 .000,00\left(^{*}\right)$ \\
\hline 2001 & $79.333 .638,00\left(^{*}\right)$ \\
\hline 2002 & $107.000 .000,00(* *)$ \\
\hline 2003 & $30.000 .000,00(* * *)$ \\
\hline 2004 & $12.000 .000,00(* * *)$ \\
\hline
\end{tabular}

Fonte: Elaboração própria com dados obtidos de (*) TCU (2003), (**)MEC (2004) e (***)Folha de S.Paulo (9 set. 2004)

Com efeito, algumas fontes consultadas, em pesquisa sobre o Programa Alfabetização Solidária, asseguravam que sua formulação surgiu dentro do Ministério da Educação. Por este entender que, pelo modelo criado, era preciso uma gestão mais dinâmica, não compatível com a máquina burocrática do Ministério, o programa teria sido oferecido à já existente Comunidade Solidária, pois, pelo modelo de gestão deste, traria facilidades na implementação. 
Considero que a ênfase em se negar o caráter governamental do Alfabetização Solidária residia no fato de o programa, como todos os outros programas derivados da Comunidade Solidária, ser um ensaio de terceirização de políticas sociais. Assim, o Alfabetização Solidária pretendia mostrar que era possível alfabetizar sem a intervenção do governo ou com apenas o financiamento de parte dos gastos, terceirizando numa "grande ONG” (a Associação de Apoio) que, por sua vez, distribuiria os recursos às Instituições de Ensino Superior (IES) para a implementação do Programa. Esse modelo permitiria também a participação das Empresas, Governos Estaduais e Instituições, provendo de fundos para Alfabetização Solidária ${ }^{8}$.

Essa "dialética" entre o governamental e o não governamental deu ao Programa uma margem importante de gestão, pois por uma parte, embora se postulasse como "não governamental", tinha o peso da Primeira Dama o legitimando e, aliás, de uma Primeira Dama nada tradicional, com uma trajetória de professora universitária que favorecia a participação das Instituições de Educação Superior. O peso governamental também influía na aceitação do Programa pelos municípios - que deviam colaborar provendo salas de aula, cadeiras, preparando merenda - pois, alguns deles, principalmente no Nordeste, não tinham interesse em alfabetizar a mão-de-obra, por exemplo, das usinas da região.

De outra parte, a independência do governo permitia ensaiar algumas estratégias tais como terceirização da implementação pelas Instituições de Educação Superior, emprego temporário, definição do tempo necessário para a alfabetização, utilização de professores leigos, pagamento com bolsas, entre outras.

\section{Empregabilidade temporária}

O Programa Alfabetização Solidária priorizou algumas decisões quanto ao seu formato que não eram intrinsecamente educacionais, por exemplo, o requisito de mudança dos alfabetizadores, que implicava que, depois de cada módulo de 6 meses, estes deveriam ser trocados (ALFABETIZAÇÃO SOLIDÁRIA, 1999). Essa decisão parece responder não a uma lógica educativa, mas à lógica da Comunidade Solidária, porque não é condizente com as teorias pedagógicas que um professor, depois de passar por um curso de capacitação e começar sua

8 É um fato que, em vários Estados, não são empresas e sim governos estaduais que financiam a metade do Programa, dependendo, então, totalmente de fundos públicos. 
experiência como alfabetizador, tenha que abandonar o seu posto, começando tudo de novo: nova seleção, novo curso.

Esse requisito foi duramente criticado em diversas instâncias, especialmente pelas Instituições de Educação Superior que implementavam o Programa, sendo debatido no Conselho Consultivo das IES parceiras.

Uma das argumentações que o Programa desenvolveu para justificar esse requisito foi o de que, sendo temporário, ele propiciava participação de um maior número de pessoas com, provavelmente, o desejo implícito de fornecer algum tipo de experiência de trabalho aos jovens de setores desfavorecidos, especialmente aqueles dos municípios do Norte e do Nordeste. Dessa forma, o desempenho de tarefas de alfabetização, como se verificou, em muitos casos tiraria o jovem da inexperiência e lhe proporcionaria seu primeiro emprego (e talvez o único).

Mas, a Comunidade Solidária já tinha desenvolvido outro programa específico de capacitação favorecendo o primeiro emprego: o Capacitação Solidária.

O Programa ${ }^{9}$ explicava também que, dessa forma, um maior número de educadores poderia viajar para as cidades de origem das IES, implicando, assim, em mais integração e melhor conhecimento das diferentes regiões. Sem questionar a validade da viagem como experiência de aprendizado, que pode até ser positiva, por que ligá-la com um programa de alfabetização? Por que não criar um programa Viagem solidária ou Integração solidária, por exemplo? Essas viagens demandavam um alto gasto ao trasladar pessoas de municípios do Nordeste, Norte e Centro-Oeste para as cidades do Sul e Sudeste (predominantemente São Paulo, que contava com o maior número de IES participantes). Será que o dinheiro não poderia ser gasto no município de origem e destinado à educação de adultos e à formação de professores?

Enfim, os critérios aqui apontados não parecem implicar na realização de um bom trabalho de educação de jovens e adultos. Antes, respondem a outra lógica: a da não valorização da experiência, pois quando o educador potencial estava começando a adquiri-la, devia ser substituído por outro alfabetizador, e começar tudo de novo. Esse tópico - a experiência - é muito importante no sucesso de qualquer tarefa educacional, principalmente no caso da alfabetização, que necessita não apenas de um professor experiente, mas, também, especializado em educação de adultos, população com características diferentes das crianças.

9 As argumentações desenvolvidas pelo Programa foram obtidas em entrevistas junto a Coordenadores de IES participantes, nas $2^{\mathrm{a}}$. $3^{\mathrm{a}}$. $4^{\mathrm{a}}$. e $5^{\mathrm{a}}$. Semanas da Alfabetização, em São Paulo (registradas em diário de campo). 
Portanto, nessa decisão do Programa, parecem ter prevalecido critérios extra-educativos: a rotatividade de alfabetizadores não gerava vínculo empregatício, o que implicava num menor custo. Concomitante a isso, a modalidade utilizada era a da bolsa, que também evitava pagamento de encargos e criação de vínculo. Inclusive, as funções de coordenador e alfabetizador eram pagas com valores inferiores aos salários de mercado. O valor das bolsas ( $\mathrm{R} \$ 300,00$ para coordenador, $\mathrm{R} \$ 120,00$ para alfabetizador do Projeto Nacional e R \$200,00 para alfabetizadores dos Grandes Centros Urbanos) era irrisório para o trabalho que demandava o Programa: em 2002, em um município da grande São Paulo, o professor de uma sala de Educação de Jovens e Adultos (EJA) recebia por volta de $\mathrm{R} \$ 1.000,00$ enquanto que o alfabetizador recebia $\mathrm{R} \$ 200,00$.

Assim, o problema dos custos, num Estado que passava por uma reforma, reduzindo e cortando gastos, aparecia como elemento central; alfabetizadores rotativos e alunos estagiários eram bem mais baratos do que professores com contratos estáveis. A manutenção deste critério no formato do Programa, desde 1997, apesar de todas as opiniões contrárias manifestas ${ }^{10}$, mostra que não se tratava de um acaso nem de um erro de concepção, senão de uma redução de custos do Programa, permitindo, ao mesmo tempo, utilizar como argumento de propaganda seu custo baixo: $\mathrm{R} \$ 34,00$ por aluno por mês, como reiteradamente anunciado na televisão, mesmo que, com isso, o Estado precarizasse suas políticas e reduzisse a qualidade da educação.

Poderia ser objetado que as viagens não implicavam em baixar os custos do Programa. No entanto, esse custo não era tão alto quanto o do vínculo empregatício e, além disso, as viagens tinham outra finalidade: legitimação pela via da cooptação.

Em síntese, o critério da mudança dos alfabetizadores (alfabetizadores descartáveis?) provêm de políticas compensatórias de empregabilidade e inclusão temporária, complementares ao modelo de Estado que a reforma propunha e que eram desenvolvidos em vários países da América Latina. A empregabilidade rotativa prevaleceu, inclusive, em detrimento da identidade pedagógica do Programa. Embora capacitação e empregabilidade temporária pudessem ser objetivos desejáveis, não poderiam comprometer o sucesso do objetivo principal do programa: a alfabetização dos jovens e adultos.

\section{Filantropia ou direito?}

10 Opiniões de coordenadores de IES entrevistados, discussão do tema no Conselho Consultivo do Programa Alfabetização Solidária (segundo vários entrevistados) e na $2^{\mathrm{a}}$. Semana da Alfabetização (2001). O Tribunal de Contas da União também opina sobre o assunto (2003). 
A Constituição de 1988 garante o direito à educação àqueles que não tiveram acesso na idade própria (art. $208^{\circ}$ inc. I), priorizando a erradicação do analfabetismo e a universalização do ensino fundamental (art. 214 ${ }^{\circ}$ inc. I.). Apesar de a Lei de Diretrizes e Bases da Educação Nacional n ${ }^{\circ}$ 9394/96 manter o direito à educação, a Emenda Constitucional n ${ }^{\circ}$ 14/96 criou o Fundo de Desenvolvimento do Ensino Fundamental e de Valorização do Magistério (FUNDEF) e subvinculou os recursos para a educação, destinando $60 \%$ deles exclusivamente para o Ensino Fundamental. A lei que regulamentou esse fundo (lei 942/96) estabeleceu que os recursos fossem distribuídos no âmbito de cada Estado e do Distrito Federal entre o Governo Estadual e os Governos municipais, proporcionalmente ao número de matriculados nas redes de ensino. Por veto presidencial a partes dos artigos da Lei 9424/96, as matrículas contabilizadas para fins do FUNDEF eram apenas as do Ensino Fundamental regular, excluindo a Educação de Jovens e Adultos, a Educação Infantil e o Ensino Médio. Assim, na prática, os Estados e Municípios priorizaram o Ensino Fundamental na faixa de 7 a 14 anos. Sem contar com recursos próprios, outros níveis de ensino como a Educação de Jovens e Adultos não foram garantidos.

Nesse contexto de descumprimento do dispositivo constitucional ("garantia de ensino fundamental obrigatório e gratuito assegurada inclusive sua oferta gratuita para todos os que a ele não tiveram acesso na idade própria" Constituição Federal da República Federativa do Brasil, Art., 208, grifo meu) um ano depois surgiu o Programa Alfabetização Solidária difundindo o seu modelo de financiamento "inovador".

Além do fato concreto de descumprimento do direito à educação dos jovens e adultos, as políticas e programas governamentais podem criar ou induzir subjetividades, com seus discursos e ações.

Com efeito, o financiamento do Programa Alfabetização Solidária constou de fundos públicos e fundos privados com destaque para os privados na difusão e propaganda da proposta. $\mathrm{Na} 2^{\mathrm{a}}$ Semana da Alfabetização, organizada pelo Programa na Cidade de São Paulo, empresários responsáveis por $80 \%$ do Produto Interno Bruto (PIB) do país se emocionavam com os relatos dos alfabetizados. Esses empresários haviam realizado doações para o Programa; da mesma forma, a campanha Adote um analfabeto (ALFABETIZAÇÃO SOLIDÁRIA, 2001) fomentava a doação das pessoas físicas, dos cidadãos individuais mediante débito de uma parcela no cartão de crédito destinada ao Programa. Assim, com esse dispositivo das doações privadas, o Programa Alfabetização Solidária convertia um direito garantido na Constituição em um ato filantrópico. De fato, entre 1997 e 2002, o Programa Alfabetização Solidária ocupou o vácuo que o Fundef não preenchia, com parte de recursos advindos do âmbito privado (de empresários e outros doadores individuais). 
Esses indivíduos, como assinala Traversini (2005, p. 8), “[...] são interpelados, nesse processo, para ocupar uma posição de sujeito: a de cidadãos solidários". Segundo a autora, a estratégia da solidariedade é utilizada para "desresponsabilizar" o Estado.

Então, doações e adoções incentivadas por meio de um programa ligado ao governo, reatualizam o modelo filantrópico de doação de dinheiro - seja de empresas ou de pessoas físicas - para causas nobres, o que, não obstante, atenta contra a educação dos adultos considerada como direito, questão recentemente incorporada, na Constituição de 1988, pois levou muitos anos para o país reconhecer essa dívida social histórica.

A promoção da filantropia e da beneficência penetrou nas IES como um discurso, às vezes, chamando alunos à solidariedade e ao sacrifício para "ajudar" os analfabetos, desenvolvendo um trabalho semivoluntário para compensar as injustiças. É muito diferente que o discurso oficial promova o acesso à educação como um direito e que o sujeito seja interpelado e considerado dessa forma: a que promova e induza dispositivos de ajuda. Isso fez com que, na prática de algumas IES, as tarefas de educar e ensinar acabassem permeadas pelo discurso da assistência, identificando-se os analfabetos como pobres, coitados, vítimas, e não de acordo com suas potencialidades como sujeitos.

No limite, isso cria ou consolida subjetividades assistidas (DUSCHATZKY, 2000), tanto no alfabetizando quanto no próprio alfabetizador e implica em uma diferença na qualidade da educação ministrada. Será que o alfabetizador planeja as mesmas estratégias tanto para um sujeito que não estudou porque não teve possibilidade quanto para um coitado? Será que ele considera que ambos têm as mesmas possibilidades de se apropriar do conhecimento?

A adoção de analfabetos, por sua vez, induziu a uma subjetividade tutelada. Um adulto adotado implica em uma visão construída não a partir da igualdade, mas da superioridade do adotante. Parece significar que a igualdade legal é inferior à desigualdade de renda. Considerar um sujeito adulto como sendo passível de adoção não é considerá-lo como um sujeito de direitos que precisa ser diferenciado apenas em estratégias pedagógicas específicas e adequadas que lhe permitam apreender como adulto, e não ser adotado.

Além de adotar analfabetos, o Programa Alfabetização Solidária chama a sua tarefa principal atender os alunos. Assim, os destinatários dele são nomeados como alunos atendidos. Isto significa que passaram pelo Programa, que em algum momento estiveram em contato com ele, o que não quer dizer que efetivamente se alfabetizaram. Esse status de aluno-atendido e não de alfabetizado é explicado pelo fato de a duração de cada módulo (6 meses) não garantir a alfabetização efetiva. Questionamentos das próprias IES levaram a reconhecer, em 2001, na $2^{\text {a }}$. Semana da Alfabetização, que não se alfabetiza nesse tempo. Em todo caso, o 
Alfabetização Solidária realiza uma sensibilização que requer a continuidade de estudos posteriores. Por isso tudo, para fins estatísticos, o aluno é um atendido, eufemismo que indica quem, de alguma forma, passou pelo Programa, sem se indicar se foi alfabetizado, evadiu-se ou continuou estudando. Assim, as cifras de 5.100.000 de alunos atendidos (<www.alfabetização.org.br>, 2006), embora importantes em quantidade, não dizem respeito à qualidade ${ }^{11}$.

Também houve indução quanto ao perfil do profissional alfabetizador de adultos. O Programa Alfabetização Solidária mostra que a figura do professor alfabetizador de adultos não é necessária. Colocou, na prática, a ideia de que a alfabetização de adultos não é uma tarefa profissional, ou seja, não precisa ser desenvolvida por um docente especializado em alfabetização de adultos, nem sequer por um professor lato sensu, contra tudo o que tem sido desenvolvido na bibliografia especializada sobre a temática nos últimos anos. Pois, qualquer pessoa, com um mínimo de treinamento, poderia realizar essa função.

Essa inclusão de pessoas quase sem experiência, em vez de professores, pretendeu ser justificada por estratégias que mostram ser possível alfabetizar com leigos. Tanto as ações pioneiras de Paulo Freire quanto as iniciativas da sociedade, como os múltiplos Movimentos de Alfabetização de Jovens e Adultos (MOVAs) e algumas ONGs, utilizam-se desses indivíduos. Mas, o Programa Alfabetização Solidária recuperou esse aspecto de uma forma descontextualizada, pois não incluiu (embora propusesse no discurso, retoricamente) a participação da sociedade na construção da proposta. Assim, o Programa chegava de cima para baixo. Nessas outras estratégias, anteriores, de alfabetização de adultos havia ou o desenvolvimento de uma metodologia de pesquisa (seleção do universo vocabular a partir da imersão na cultura), ou os questionamentos das condições de vida, ou, ainda, a motivação de mudança social, como na época do desenvolvimento das experiências pioneiras de Paulo Freire e da participação popular dos MOVAs. Mas, a eleição de leigos, no Programa Alfabetização Solidária, também parece estar regida pelo princípio do baixo custo e da filantropia.

\section{Considerações finais}

As experiências de educação e alfabetização de adultos no Brasil, desde meados do século XX, mostram o quanto a educação dos adultos demorou a

11 Como, de fato, alguns participam mais de um semestre, a cifra de 5.100 .000 pode contabilizar alguns, mais de uma vez. 
ser incorporada como direito com a Constituição de 1988, e que rapidamente as intenções de priorizar a erradicação do analfabetismo foram sepultadas pelas políticas de educação, no final da década de 1990. A educação dos adultos foi excluída das matrículas contabilizadas para o financiamento e, portanto, das prioridades educacionais.

Mas, os compromissos internacionais levaram à necessidade de criar ações que atendessem à reversão das cifras alarmantes do país, quanto ao analfabetismo. A lógica de ajuste das políticas sociais e, especialmente, educacionais do governo Fernando Henrique Cardoso implicou na criação de uma alternativa baseada no menor custo. Assim, a educação de jovens e adultos, conceito que busca superar a mera alfabetização e que reconhece a necessidade de educação formal durante um período maior que o da alfabetização (pelo menos 4 anos), foi desconsiderada. Concentraram-se, então, os esforços governamentais visando à redução do analfabetismo, na formatação de uma estratégia ${ }^{12}$ instalada na órbita social-assistencial do governo - a Comunidade Solidária -, e não na educacional, utilizando-se da figura da esposa do Presidente, que tinha uma trajetória profissional e acadêmica ligada a movimentos sociais, para mobilizar outras instâncias e instituições e, assim, fugir do modelo de instalação de uma rede de educação. O Programa Alfabetização Solidária buscou a implementação de um modelo de terceirização de políticas educacionais, no caso, de alfabetização de jovens e adultos, utilizandose das Instituições de Educação Superior com essa finalidade.

Esse Programa priorizou critérios de menor custo, empregabilidade temporária e filantropia. Também, induziu subjetividades, diferentes daquelas que definem os analfabetos como sujeitos de direito. Assim, recuperou tanto o discurso assistencialista da ajuda quanto a tutela, por meio da adoção de adultos, e, finalmente, definiu os seus alunos como atendidos e banalizou a figura do alfabetizador.

\section{REFERÊNCIAS}

ALFABETIZAÇÃO SOLIDÁRIA. Escrevendo juntos, n. 17, Brasília, jul./ ago. 2001.

12 Segundo Franco (1998), Comunidade Solidária não era um Programa e sim uma estratégia de tratamento de gestão. 
ALFABETIZAÇÃO SOLIDÁRIA. Conselho Consultivo das Universidades parceiras. Revista Cientifica: Princípios Orientadores para Elaboração da Proposta Político Pedagógica, Brasília, 1999.

BANCO INTERAMERICANO DE DESARROLLO (BID). Modernización del Estado y fortalecimiento de la sociedad civil. Washington: BID, [19-?].

BARREYRO, G. B. Políticas sociais e educação: O Programa Alfabetização Solidária e a participação das instituições de ensino superior na sua implementação. Tese (Doutorado em Educação) - Faculdade de Educação, Universidade de São Paulo, São Paulo, 2005.

BARRETO, M. I. As organizações sociais na reforma do Estado brasileiro. In: PEREIRA, L. C. B.; CUNILL GRAU, N. (Orgs.) O público não estatal na Reforma do Estado. Rio de Janeiro: Fundação Getúlio Vargas/Clad, 1998.

BRASIL. Emenda Constitucional $N^{o} 14$, de 12/09/96. Modifica os artigos 34, 208, 211 e 212 da Constituição Federal e dá nova redação ao artigo 60 do Ato das Disposições Constitucionais Transitórias. Disponível em: <http://portal. mec.gov.br/arquivos/pdf/e1496.pdf>. Acesso em: 20/2/2009.

BRASIL. PRESIDÊNCIA DA REPÚBLICA, CÂMARA DA REFORMA DO ESTADO. Plano Diretor da Reforma do Aparelho do Estado. Brasília, 1995.

BRASIL. Constituição da República Federativa do Brasil. São Paulo: Imprensa Oficial, 1999.

BRASIL. Lei de Diretrizes e Bases da Educação: 9394/96. Rio de Janeiro: Ed. Esplanada, 1998.

BRASIL. Lei 9424 de 24.12.96. Dispõe sobre o Fundo de Manutenção e Desenvolvimento do Ensino Fundamental e de Valorização do Magistério. Diário Oficial da União, Brasília, DF, 26 dez. 1996.

CARDOSO, R. Palestra proferida na Segunda Semana da Alfabetização, São Paulo, 4/9/2001, (nota de campo).

CARDOSO, R. Fomentando parcerias por um Brasil melhor. Disponível em: $<$ http://www.comunidadesolidaria.org $>$. Acesso em: 15/7/2000.

DI PIERRO, M. C. Descentralização, focalização e parceria: uma análise das tendências nas políticas públicas de educação de jovens e adultos. Educação e pesquisa, São Paulo: FEUSP, v. 27, n. 2, p. 321-337, jul./dez., 2001. 
DUSCHATZKY, S. (Org.). Tutelados y asistidos. Programas sociales, políticas públicas y subjetividad. Buenos Aires: Paidós, 2000.

FALCÃO, J.; CUENCA, C. (Orgs.). Mudança social e reforma legal. Estudos para uma nova legislação do Terceiro Setor. Brasília: Conselho da Comunidade Solidária- Unesco-BID, 1999.

FERRARESI, E. OSCIP: Organização da sociedade civil de interesse público: a lei 9790/99 como alternativa para o terceiro setor. Brasília: Comunidade Solidária, 2000.

FOLHA DE S. PAULO. Ong brasileira recebe prêmio de alfabetização. São Paulo, C5, 9/9/2004. Disponível em: <http://www1.folha.uol.com.br/folha/ educacao/ult305u16029.shtml>. Acesso em: 20/2/2009.

FRANCO, A. O caráter inovador dos Programas da Comunidade Solidária. Estratégias inovadoras de parceria no combate à exclusão social. Avaliação, diálogo e perspectivas. Brasília: Comunidade Solidária-Pnud-UNESCO, 2000.

FRANCO, A. Construindo uma nova relação Estado-Sociedade. A experiência do Conselho da Comunidade Solidária. Draft-paper, $3^{\mathrm{a}}$ versão. Brasília: Conselho da Comunidade Solidária, 1998.

MINISTÉRIO DA EDUCAÇÃO. Brasil alfabetizado. Disponível em: <http:// www.mec.gov.br>. Acesso em: 8/9/2004.

PAIVA, J.; MACHADO, M. M.; IRELAND, T. (Orgs.). Introdução. Educação de Jovens e Adultos: uma memória contemporânea. Brasília: Unesco-MEC, 2004.

PEREIRA, L. C. B. Da administração pública burocrática à gerencial. In: PEREIRA; L. C. B.; SPINK, P. (Orgs.). Reforma do Estado e administração pública gerencial. Rio de Janeiro: Fundação Getúlio Vargas, 1998.

REPÚBLICA. Ainda um país de analfabetos. v. 5, n. 55, p.38-41, maio 2001.

SOARES, L. Educação de jovens e adultos. Diretrizes Curriculares Nacionais. Rio de Janeiro: DP\&A, 2002.

TRAVERSINI, C. Debite um analfabeto no seu cartão: a solidariedade como estratégia para alfabetizar a população e desresponsabilizar o Estado. In: REUNIÃO ANUAL DA ANPED, 28, 17-19 de outubro de 2005, Caxambú. 
Anais... Caxambú, 2005. Disponível em: <http:// www.anped.org.br >. Acesso em: 15/11/2005.

TRIBUNAL DE CONTAS DA UNIÃO. Avaliação do TCU sobre a Alfabetização Solidária de Jovens e Adultos. Brasília: TCU, 2003.

\section{Sites}

ALFASOL. Disponível em: <http://www.alfabetizacao.org.br>. Acesso: desde 2002 até 2006.

COMUNITAS. Disponível em: <http://www.comunitas.org.br>. Acesso em: 2004.

SourceForge. Disponível em: <http://www.comunitadesolidaria.org.br $>$. Acesso: entre 2001e 2002.

Texto recebido em 12 de novembro de 2008 .

Texto aprovado em 02 de dezembro de 2008. 